Revue d'histoire de l'Amérique française

REVUE D.HISTOIRE DE L'AMÉRIQUE FRANÇAISE

\title{
Chronique des fêtes du centenaire
} L’année du centenaire Lionel-Groulx, 1978

\section{Jean-Pierre Wallot}

Volume 32, numéro 3, décembre 1978

Lionel Groulx, $100^{\mathrm{e}}$ anniversaire de sa naissance, 1878-1978

URI : https://id.erudit.org/iderudit/303725ar

DOI : https://doi.org/10.7202/303725ar

Aller au sommaire du numéro

Éditeur(s)

Institut d'histoire de l'Amérique française

ISSN

0035-2357 (imprimé)

1492-1383 (numérique)

Découvrir la revue

Citer ce document

Wallot, J.-P. (1978). Chronique des fêtes du centenaire : l'année du centenaire Lionel-Groulx, 1978. Revue d'histoire de l'Amérique française, 32(3), 527-528.

https://doi.org/10.7202/303725ar d'utilisation que vous pouvez consulter en ligne.

https://apropos.erudit.org/fr/usagers/politique-dutilisation/ 


\section{CHRONIQUE DES FÊTES L'année du centenaire Lionel-Groulx 1978}

L'historien n'a guère la renommée longue. Très tôt, la plupart du temps de son vivant, on conteste ses hypothèses, ses méthodes, ses conclusions. On reprend la reconstruction inlassable du passé ou encore on complète les ouvrages antérieurs ou on réorganise les matériaux. C'est que le passé prend son sens dans le présent, dans les inquiétudes et les espoirs de demain. Aussi les historiens prennentils l'habitude d'oublier ou de rapetisser leurs prédécesseurs, sans compter les coups qu'ils portent avec plus ou moins d'efficacité à leurs contemporains qui osent penser différemment. Cette pratique comporte des avantages (refus du conformisme, diversité des approches, renouvellement des hypothèses) et des inconvénients (recommencements souvent futiles, querelles de mots, etc.). Mais elle fait partie intégrante du métier de l'historien. C'est en elle-même une histoire.

Occasionnellement, un historien échappe à l'hécatombe. Non qu'on ne s'en prenne à ses écrits, voire à sa personne. Mais ses oeuvres ont provigné dans tellement de directions, ont tellement marqué la mentalité d'une époque qu'on ne peut plus étudier cette période sans faire référence à l'historien-acteur-penseur qui y fut miroir et principe d'action. Lionel Groulx fait partie de ce groupe de quelques historiens qui, sans faire l'unanimité, commandent le respect de leurs successeurs. Ces derniers profitent d'ailleurs, comme dans le cas de Groulx, non seulement de ses travaux historiques, mais d'oeuvres encore bien vivantes d'une autre nature : l'Institut d'histoire de l'Amérique française, qui regroupe la plupart des historiens actifs en histoire nationale au Québec, et la Revue d'histoire de l'Amérique française, qui sert de débouché à une proportion importante de leurs travaux de qualité. 
Il n'est donc guère surprenant que, dès 1977, la Fondation Lionel-Groulx et l'Institut d'histoire de l'Amérique française aient mis sur pied un comité chargé de coordonner les fêtes du centenaire de la naissance de Groulx en 1978. Ces célébrations, fort nombreuses, se sont déroulées dans tous les coins de la province. Avant d'en donner une liste sommaire, cependant, il convient de souligner le succès retentissant du concours Lionel-Groulx aux niveaux secondaire et collégial, la qualité exceptionnelle des travaux qui ont été soumis (certains sont publiés dans la présente livraison), l'enthousiasme très vif des jeunes pour l'histoire, qui a convaincu la Société des professeurs d'histoire du Québec et le Ministère de l'Éducation du Québec de continuer ce concours annuel à l'avenir, avec des thèmes variés. Réveiller l'intérêt pour l'histoire nationale, voilà sans doute une réussite fort pertinente en une année marquant le centenaire de naissance de notre "historien national". 